\title{
Formação de professores na escola básica: desafios cotidianos na atuação da professora-coordenadora*
}

\section{Continuing education for teachers in primary school: daily challenges in the performance of the teacher-coordinat}

\author{
Heloísa Helena Dias Martins Proença
}

Mestranda em Educação (Unicamp) e coordenadora pedagógica na rede privada de ensino heloisamartinsproenca@gmail.com

\section{Resumo:}

O artigo apresenta alguns apontamentos sobre a formaçáo de professores que ocorre no interior da escola básica, alicerçados na experiência de um grupo de professorascoordenadoras que atuam nas redes pública e privada de ensino, que se reúne para dialogar e refletir sobre o próprio trabalho. A realidade multifacetada e desafiadora da instituiçâo escolar atravessa o papel da professora coordenadora e influencia as ações de formação que decorrem de sua função. Para compor os apontamentos, as professoras-coordenadoras rememoram e constroem uma narrativa de seu trabalho apresentando quais princípios norteiam seus saberes-e-fazeres.

Palavras-chave: Formação de professores; Coordenador pedagógico; Cotidiano escolar
Abstract:

The article presents some notes on the teacher training that occurs within the primary school, grounded in the experience of a group of teachers, coordinators who work in public and private schools, who meet to talk and reflect on their own work. The challenging and multifaceted reality of the school through the role of coordinator and teacher training influences the actions arising from its function. To compose the notes, teachers, coordinators recall and construct a narrative of your work showing what principles guide their knowledge-anddoings.

Keywords: Continuing education of teachers; Educational coordinator; School every day

\footnotetext{
* Trabalho apresentado no GT Memória e Formação de Professores
} 
1 - Participam dessa reflexão, além da autora, as professoras Adriana Stella Pierini, Cláudia Roberta Ferreira, Márcia Alexandra Leardine, Maria Natalina Oliveira Farias e Patrícia Regina Infanger Campos. Tratase de um grupo de professoras-coordenadoras e pesquisadoras que integram o Gepec (Grupo de Estudos e Pesquisas em Educação Continuada), vinculado ao Programa de Pós-graduação da Faculdade de Educação da Universidade Estadual de Campinas - Unicamp.
Tudo que os livros me ensinassem os espinheiros já me ensinaram. Tudo que nos livros eu aprendesse nas fontes eu aprendera. O saber não vem das fontes? Manoel de Barros (2003)

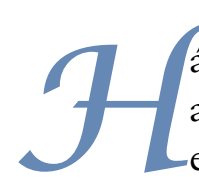

á mov á movimento comum que nos toca, nos incomoda, nos articula, nos arremessa “às fontes”, conforme diz o poeta na epígrafe: o de compreendermos o processo de formação de professores que acontece no cotidiano das escolas nas quais estamos inseridas [1]. Partilhamos inquietaçóes desse/nesse lugar de professoras-coordenadoras, compreendendo a responsabilidade de nosso trabalho, tal como nos aponta GEGLIO (2008: 115) ao referenciar que "o coordenador pedagógico exerce um relevante papel na formação continuada do professor em serviço, e esta importância se deve à própria especificidade de sua função, que é planejar e acompanhar a execução de todo o processo didático-pedagógico da instituição".

Compreendemos que a qualidade dessa especificidade em nossa função de professoras-coordenadoras está atrelada aos princípios que norteiam nosso trabalho. Estes qualificam nossa atuação no cotidiano escolar e definem os rumos desta. Ressaltamos, também, que "não se trata mais de administrar pessoas, mas de administrar com as pessoas. As organizaçôes cada vez mais precisam de pessoas proativas, responsáveis, dinâmicas, inteligentes, com habilidades para resolver problemas, tomar decisōes" (CHIAVENATO, 1997: 101).

Mobilizadas por este desejo de coordenar com as pessoas, na direção da construção de um projeto pedagógico em favor da aprendizagem das crianças, e potencializando a formação profissional e pessoal dos adultos profissionais, organizamos encontros fora da escola para dialogarmos sobre nossos fazeres-e-saberes de professoras-coordenadoras como parceiras de atuaçáo cotidiana. Isto porque acreditamos nos espaços de diálogo também a partir das referências profissionais comuns neste lugar de coordenação pedagógica, que se difere do ponto de vista do exercício da docência.

Nos encontros viabilizados pelo Gepec, o diálogo nos ajuda a elucidar princípios e crenças a respeito do papel da coordenação pedagógica no contexto da escola, possibilitando a ampliação de nossas referências sobre o nosso próprio trabalho, bem como a sistematização das mesmas. Durante nossos processos de estudo-reflexão-discussão esforçamo-nos para não perder de vista a importância de discutir a formação continuada docente a partir de pressupostos que têm como matriz de referência a docência e a busca de um processo educativo escolar que valorize a aprendizagem efetiva de todos os alunos.

Aproximamo-nos porque queremos dialogar em nossas diversidades de saberes-fazeres, sobre aquilo que produzimos (ou náo) junto aos professores e aos alunos nas escolas, onde estamos envolvidas. Optamos por investigar o nosso próprio trabalho, pois acreditamos que elucidar e ter clareza daquilo que sabemos sobre ele, sobre nossas tarefas, atividades, intervençóes, desafios, silêncios e questionamentos é conhecimento construído na prática e intervêm diretamente em nossas escolhas, as quais interferem, por sua vez, nas açóes cotidianas no interior de nossas escolas. Além disso, ajudam-nos a ter maior clareza dos princípios que fundamentam nosso fazer-e-saber profissional. 
Para compor os apontamentos aqui explicitados, rememoramos e construímos uma narrativa de trabalho que apresenta princípios comuns que norteiam nossos saberes-e-fazeres, concordando com a ideia de Larrosa de que "La educación es la construcción y la re-construcción de historias personales y sociales" (LARROSA, 1995: 13). Entendemos que as narrativas aqui apresentadas são memórias de um contexto, de um tempo, de individualidades e singularidades. São memórias que dão a ver a dimensão social, política e educacional de um espaço, situado historicamente. Memórias de "si" que dizem das memórias de um "nós" numa perspectiva em que se busca evidenciar as diferentes vozes e os múltiplos olhares de quem vivencia e pratica, portanto, experiencia o cotidiano da escola e por isto mesmo, pode projetar em um horizonte de possibilidades, uma memória de futuro.

Memórias que revelam nossos percursos de formação pessoal e profissional, também gerados pelas diversas possibilidades de estudos dentro do GEPEC, que, desde sua criação, desenvolve pesquisas que concebem o trabalho docente numa relação dialógica entre teoria-prática-teoria/prática-teoria-prática.

Quais memórias pretendemos compartilhar? Memórias de pesquisa, estudo e trabalho em uma perspectiva coletiva, dialógica e produtora de conhecimentos sobre e no cotidiano escolar.

\section{Princípios compartilhados de atuaÇáo DA PROFESSORA-COORDENADORA: AQUILO QUE NOS MOBILIZA}

O que interessa não são os "grandes" contrastes, e sim os contrastes dialéticos, que frequentemente se confundem com nuances. A partir deles, no entanto, recria-se sempre a vida de novo.

Walter Benjamin (2009)

Primeiramente, acreditamos que nossos encontros se tornaram possíveis porque comungamos da ideia-referência de que a escola é um espaço privilegiado de relações humanas, repleto de possibilidades, criaçóes e invençóes. Acreditamos que no cotidiano escolar, o professor produz saberes e conhecimentos, portanto, faz pesquisa ao compartilhar seus saberes com outros sujeitos que convivem no mesmo espaço no desenvolvimento de um trabalho e "numa pesquisa em que o eu sozinho náo existe, porque todo trabalho formativo acontece no coletivo e com a contribuição e participação do outro. Nenhuma formação acontece com um sujeito apenas" (CAMPOS, 2010: 10).

Dessa forma, pautamo-nos no princípio de que as interaçóes entre os sujeitos que compóem a estrutura escolar proporcionam trocas de saberes-e-fazeres e novas aprendizagens. Ao organizar os espaços e tempos escolares, de maneira a favorecer interaçóes e trocas entre professores e demais sujeitos, a professora-coordenadora também vislumbra a formação dentro da escola. Cunha (2006: 35) destaca que "as coordenadoras pedagógicas são interlocutoras privilegiadas entre os professores em suas reflexóes sobre a prática”. Destaca, também, que, a função principal do coordenador pedagógico

é promover a formação continuada dos professores no interior da escola. A coordenadora pedagógica é convocada 
a assumir sua tarefa de formadora de professores e a escola passa a constituir-se como cenário para as mudanças necessárias para a educação (CUNHA: 2006: 35).

Entendemos que estas mudanças são as que ocorrem em diferentes instâncias que perpassam as especificidades e necessidades individuais, congregando crenças e objetivos a favor da organizaçáo de uma escola e de seu projeto pedagógico. Eis mais dois princípios importantes sobre a atuação da professora-coordenadora voltada para a formaçáo no espaço escolar: o respeito às diferenças individuais e a necessidade do diálogo.

Compartilhamos com a ideia de GERALDI (2003) e assim como ele, pretendemos perseguir a "intuição" de que nos discursos se encontram o que costumamos dicotomizar, explicitando a concepção de linguagem que sustenta intuiçóes e análises.

Todo sujeito é resultado das experiências vividas e das aprendizagens construídas. Possui diferentes percursos de formação pessoal e profissional. Os professores que constituem uma escola também apresentam diferentes percursos de formação porque são, e também somos, inconclusos e limitados, estamos em permanente aprendizado e desenvolvimento.

A partir dessa temática, apropriamo-nos dos conceitos de CERTEAU (2008: 35), para entender que "O caminhar de uma análise inscreve seus passos, regulares ou ziguezagueantes, em cima de um terreno habitado há muito tempo". Esse mesmo autor nos atenta para as astúcias anônimas da "arte de fazer", pois nelas residem as resistências dos sujeitos frente às imposições do dia-a-dia das esferas sociais onde estão inseridos.

Daí decorre a importância fundamental que nos "completa" em nossa incompletude: o diálogo, a relação com o outro, a dialogia e a alteridade. É necessário que a professora-coordenadora fique atenta às individualidades dos professores com quem trabalha, para poder colaborar com a/na construção de um grupo efetivo de trabalho, sem a intenção de generalizar as características pessoais e tornar o grupo homogêneo. Afinal, aprendemos muito com a diversidade.

Segundo CLEMENTI (2003: 56) a professora-coordenadora precisa

estimular e criar situaçóes para que se realizem debates amplos e definiçóes sobre a estrutura da escola, seu funcionamento e suas relaçóes com a sociedade. Além disso (...) a sensibilização para a importância da construção de um projeto comum aos indivíduos que circulam e/ ou atuam no espaço escolar, que oriente atividades, valores, atitudes, procedimentos, organização funcional e relacionamentos interpessoais, envolvendo colaboração, comprometimento e diálogo.

Um projeto comum de escola somente efetiva-se quando existe espaço para discussão, trocas de saberes-e-fazeres e trabalho coletivo, quando são estabelecidas relaçóes de recíproco respeito e admiração. Todos podem aprender e aprendem na interação com o outro. Entendemos que as condiçôes para que isso aconteça necessitam ser criadas (e constantemente recriadas) para que, a partir da explicitação dos saberes-e-fazeres, seja potencializada a reflexão sobre as práticas. 
Um terceiro princípio é a tentativa de promover uma prática reflexiva por meio do diálogo e das narrativas (orais, escritas, imagéticas); por isso reforçamos, mais uma vez, a importância do diálogo no espaço escolar. Debater, narrar, promover uma prática reflexiva enquanto possibilidade educativa, acirrando o debate, no cotidiano escolar, a respeito de questôes inquietantes deste cotidiano, são açóes que ampliam nossas aprendizagens, nossa formação. Através do diálogo expomos inquietaçóes, problemas, dilemas, dúvidas, alegrias, conquistas, sofrimentos e, porque expomos, (com)partilhamos. Por estas exposiçóes, essas narrativas produzidas, podemos vislumbrar (im)possibilidades, alternativas, caminhos, enfim, produzir novos conhecimentos.

As narrativas produzidas por esses autores dialogam com a nossa sociedade e exprimem as realidades, as identidades culturais por nós vivenciadas. $\mathrm{Na}$ tentativa de agir para compreender o nosso cotidiano, de professores, de alunos, dos envolvidos neste processo formativo, buscamos o como e o que podemos realizar, no lugar de professoras-coordenadoras para potencializar o processo de ensino e aprendizagem de todos os envolvidos.

Fazer uso dos 'diálogos' tem-nos ajudado a buscar as tramas e os fios que tecem as narrativas dos professores, pessoas com os quais estamos diretamente ligadas e temos o compromisso de auxiliá-los a pensar a escola que temos, o que fazemos e a escola que queremos.

Coordenar o pedagógico implica em redirecionamento e esclarecimento coletivo do sentido da escola. Jamais conseguiremos fazê-lo sozinhas, por mais competência que tenhamos, se a instituição e seus contornos administrativos-políticos, não estiverem também comprometidos, envolvidos e conscientes dos princípios pedagógicos que a equipe elegeu para conduzi-los.

Através da interação e do diálogo, "narrador e ouvinte compartilham um fluxo narrativo comum, aberto a novas propostas, que podem emergir a cada uma de suas passagens. Cada acontecimento, cada personagem sugere, suscita história, que articulam e se constituem entre si, tecendo em rede" (FONTANA: 1997, 51).

Acreditamos ser nossa função promover uma prática na qual essas intençôes sejam evidenciadas pela própria equipe, apropriadas pelo coletivo, num processo contínuo de busca de convergência e negociação de projetos e açôes. Ao realizarmos esta prática reflexiva, possibilitamos que os professores debatam sobre novos/outros elementos que re-significam as histórias, as culturas desses sujeitos. O que buscamos não é somente trazer informações sobre estas histórias, mas sim, estimular o "despertar" em todos que se sentem parte integrante dessa história, para produzirmos outros sentidos, relaçóes, nexos.

As narrativas produzidas nos diálogos são capazes de articular dimensões temporais, espaciais, pessoais. Elas trazem à tona a dimensão do sujeito nas instituições e na vida em sua relação com o social, pois a "experiência individual não está isolada da experiência social, é conjunto de características próprias e variadas de experiências singulares que a realidade social manifesta" (WITTIZORECKI et al., 2006: 10).

A experiência que provém da narrativa é constituinte do próprio sujeito. Ela possibilita maior conhecimento de quem somos e isso acontece porque

somente em relação a outro indivíduo tornamo-nos capazes de perceber nossas características, de delinear nossas peculiaridades pessoais e nossas peculiaridades profissio- 
nais, de diferenciar nossos interesses das metas alheias e de formular julgamentos sobre nós próprios e sobre nosso fazer. A partir do julgamento que outros fazem de nós, do julgamento que fazemos dos outros, percebendo o julgamento dos outros sobre nós próprios, tomamos consciência de nós mesmos, de nossas especificidades e de nossas determinaçōes (FONTANA: 1997, 68).

Narrar o cotidiano é também pesquisar e gerar novos-outros saberes e conhecimentos.

A narrativa é tanto um fenômeno quanto uma abordagem de investigação-formação, porque parte das experiências e dos fenômenos humanos advindos das mesmas. O que é a educação senão a construção sócio-histórica e cotidiana das narrativas pessoal e social? O cotidiano humano é, sobremaneira, marcado pela troca de experiências, pelas narrativas que ouvimos e que falamos, pelas formas como contamos as histórias vividas (SOUZA: 2006, p. 97).

Narrativa que visa tanto apresentar uma experiência de formação docente, quanto contribuir para a continuidade do processo formativo, pois acreditamos que

as narrativas ganham sentido e potencializam-se como processo de formação e de conhecimento porque têm na experiência sua base existencial. Desta forma, as narrativas constituem-se como singulares num projeto formativo, porque se assentam na transação entre diversas experiências e aprendizagens individual/coletiva. A arte de narrar inscreve-se na subjetividade e implica-se com as dimensôes espaço-temporal dos sujeitos quando narram suas experiências (SOUZA: 2006, p. 94).

Os fundamentos teórico-metodológicos das narrativas, da valorização da experiência, da reflexividade e do desenvolvimento pessoal e profissional pautam-se numa visão outra de compreensão da complexidade do cotidiano escolar, um cotidiano que, ao mesmo tempo em que aprisiona, também pode libertar.

Essa visão agrega princípios de que o sujeito que constitui a estrutura escolar é provido de experiências pessoais e profissionais, de memórias de formação que o auxiliam na compreensão do passado e do presente e vislumbram possibilidades formativas de futuro, se assumir um papel ativo na escola, papel de professor que age, troca experiências, reflete, modifica seus saberes-e-fazeres, forma-se e contribui na formação do coletivo, pois

náo posso viver do meu próprio acabamento e do acabamento do acontecimento, nem agir; para viver preciso ser inacabado, aberto para mim - ao menos em todos os momentos essenciais -, preciso ainda me antepor axio- 
logicamente a mim mesmo, não coincidir com a minha existência presente. (BAKHTIN, 2003: 11)

Foi acreditando neste movimento que possibilita refletir sobre/com/em ação que iniciamos um processo de construção de saberes sobre a atuação da professora-coordenadora, participando de um grupo que nos ajuda a (re)construir nosso fazer e nossos saberes, impulsionando nossas açóes e fortalecendo nossos princípios. Percebemos que nosso fazer-saber vai se transformando porque nos aprofundamos em sua especificidade, em seus nuances. É no diálogo em conjunto que nossas ideias vão se tornando mais claras e nos ajudam a compreender melhor o cerne de nosso trabalho. Mas, de que diálogo falamos?

Falamos do movimento de 'pensar alto' sobre o próprio trabalho, de partilharmos experiências vivenciadas na escola, de narrarmos o vivido, ponderando sucessos e fracassos, tentativas e aprendizagens.

Falamos da possibilidade de, ao escutarmos umas às outras, pensarmos e falarmos sobre cada uma de nós, problematizando questóes cotidianas, buscando compreender porque fazemos o que fazemos, desvelando as teorias implícitas em cada uma de nossas açóes na escola.

Falamos da oportunidade de relativizar certezas, construir novas dúvidas, consolidar, de fato, conhecimento legítimo a partir do que se faz e não a partir daquilo que 'deve ser feito'.

E, ao falarmos e ouvirmos, desestabilizamos algumas crenças, reorientamos fazeres-e-saberes e vivenciamos um coletivo de maneira diferente do que experimentamos na escola, porque falamos e ouvimos de um mesmo lugar profissional: o lugar de professoras-coordenadoras.

\section{“As TÁTICAS PRATICANTES”... AQUILO QUE NOS ORIENTA}

Todas nós iniciamos nossa vida profissional como professoras. Desenvolvíamos um trabalho pedagógico que nos desafiava no contexto de sala de aula e extrapolava para seu entorno. Cada uma de nós, com caminhos profissionais diferentes, chegou à coordenação pedagógica acreditando que poderia partir das experiências na docência para construir uma prática profissional de coordenar o trabalho pedagógico na escola, sem deixar de lado a preocupação em favorecer aos professores um lugar de destaque em todas as açóes que compóem as escolhas que fazemos coletivamente em nossas escolas. Neste outro lugar profissional, re-conhecemos um excedente possível de visão da sala de aula e, dada a vivência neste lugar como docentes, assumimos a matriz de referência de nossa constituição na condição de professoras-coordenadoras.

O excedente de visão é o broto em que repousa a forma e de onde ela desabrocha como uma flor. Mas para que esse broto efetivamente desabroche na flor da forma concludente, urge que o excedente de minha visão complete o horizonte do outro indivíduo contemplado sem perder a originalidade deste. Eu devo entrar em empatia com esse outro indivíduo, ver axiologicamente o mundo de dentro dele tal qual ele o vê, colocar-me no lugar dele e, depois de ter retornado ao meu lugar, completar o horizonte dele com o excedente de visão que desse meu lugar se descorti- 
na fora dele, convertê-lo, criar para ele um ambiente concludente a partir desse excedente da minha visão, do meu conhecimento, da minha vontade e do meu sentimento (BAKHTIN, 2003: 23).

Buscamos compreender os acontecimentos na perspectiva da experiência como conhecimentos produzidos no cotidiano das escolas. Dar a ver nossas "táticas de praticantes" (CERTEAU, 2008) em nosso viver do cotidiano. As escolhas que fazemos não são aleatórias e casuais. Olhamos a partir de dentro da escola; vendo-nos nela, afastam-nos para vermos como atuamos neste espaço; neste sentido, os encontros com este grupo de professoras-coordenadoras no GEPEC potencializam que coloquemos em prática o excedente de visão, em relação ao nosso próprio saber-fazer-saber.

Mas o que fazemos? O que produzimos em nossas escolas?

Considerando pesquisas e textos - dentre os quais destacamos as produçóes de Vera Placco, Renata Cunha, Patrícia Campos e Adriana Pierini - sobre a atuação do professor-coordenador, objetivamos dialogar sobre os dispositivos que criamos, cotidianamente, para alterar, interromper uma rotina, recriá-la e produzir visibilidade dos saberes-e-fazeres dos nossos professores. "Um jeito de fazer" a ser aperfeiçoado na circulação da diversidade das práticas, por nós sujeitos da escola, por entendermos que podemos aprender com a prática do outro. Partilhamos, também, da ideia de que a formação é uma responsabilidade compartilhada, pois o coletivo se configura como potência ao confluir princípios e definição de ações e de projetos.

Ressaltamos que em nossos encontros de estudo, através das narrativas e diálogos, identificamos práticas próximas, articuladas entre si, que indicam as primeiras liçóes deste exercício de (com)partilhar nossos fazeres-e-saberes de professoras-coordenadoras, aqui apresentadas topicalizadas:

a) Promover a experiência da escrita docente;

b) Possibilitar a afirmação dos sujeitos sobre suas práticas e a reflexão sobre elas em espaços coletivos;

c) Oportunizar espaço-tempo para ampliação do repertório cultural dos adultos profissionais;

d) Garantir o acompanhamento "cuidadoso" do trabalho desenvolvido em sala de aula pelo professor;

e) Participar da elaboração de projetos com o professor;

f) Valorizar a multiplicidade de experiências cotidianas;

g) Potencializar e abrir espaço para o diálogo;

h) Promover uma prática reflexiva sobre a própria prática;

i) Trabalhar com o professor e demais membros da equipe educativa.

\section{As PRIMEIRAS LIÇÓES (COM)PARTILHADAS NOS ENCONTROS: POSSIBILIDADES DE DIÁLOGO, PARCERIA E INTERLOCUÇÃO}

Pensamos que a avaliação e a autoavaliação precisam fazer parte de nosso cotidiano e podem ser promovidas por meio de vídeos, gravaçóes, análises de aulas, compondo um conjunto de narrativas múltiplas (verbais, orais, visuais), que possibilitam percebermos como agimos, analisar o silêncio... onde todos são convocados a ler, reler, interpretar e compreender o processo que está sendo realizado, que saberes-e-fazeres são explicitados. 
Um breve texto como este, que relata uma experiência concreta fundamentada na reflexão, não é possível, neste momento, ser finalizado com uma conclusão. Podemos, no máximo, socializar algumas consideraçóes que acreditamos serem relevantes para uma prática escolar mais humanizada em favor da aprendizagem das crianças e potencializando a formaçáo profissional e pessoal dos adultos profissionais.

Como experiência humana, temos a certeza de não havermos esgotado as possibilidades do refletir e de colocar em prática nossas ideias, mas compartilhamos a possibilidade de fazer diferente, promovendo um trabalho compartilhado e reflexivo, que acredita no potencial criativo da escola e deste lugar como promotor de conhecimento e que, por isso mesmo, precisa ser mais compartilhado e divulgado.

Acreditamos que promover diálogos, estudos, reflexóes, com a perspectiva de trabalho que desenvolvemos possibilita o encontro, confrontos, enfrentamento dos dilemas e conquistas que realizamos, dentro do espaço escolar, interferindo favoravelmente no desenvolvimento profissional e pessoal dos envolvidos, proporcionando uma relação efetiva entre aquilo que se aprende e as possíveis relaçóes sociais que podemos estabelecer, abrindo espaços para que diferentes contextos sociais façam parte da realidade escolar, visando, assim, o desenvolvimento social e a valorização humana dos sujeitos.

Desejamos que esta experiência, mesmo passível de equívocos, possa ser tomada para uma reflexão acerca de valores ligados às vivências e à prática no cotidiano escolar, contribuindo para o exercício da coordenação pedagógica, na perspectiva de um trabalho coletivo e reflexivo, e que vocês leitores encontrem nestas páginas, energia suficiente para o trabalho com a coordenação, promovendo açôes educativas que superem os dogmas sociais, abrindo-se às novas dimensões do trabalho da/na escola com os professores.

Acreditamos que a escola é lugar em que se passa um processo de socialização intenso que se confunde com o eu, não havendo ser humano que não aprenda com a experiência. Tomamos a experiência como ponto de partida, mas sabemos que é um grande desafio e precisamos, inclusive, desaprender muitas coisas que já sabemos e defendemos a ideia que nós professores, coordenadores ou não, carregamos conosco muitos aprendizados e, portanto, precisamos compartilhar o que pensamos, o que fazemos e no contato com os outros e outras experiências, conseguirmos nos distanciar da própria experiência, compreendendo, questionando, debatendo, refletindo com a experiências dos outros, para poder ver e compreender a nossa mais de perto.

Uma última consideração refere-se à constante necessidade de aprofundamento nos estudos, o que nos possibilita relacionar os fundamentos teóricos de planejamento, currículo e unidade didática com a prática pedagógica, a partir de experiências efetivadas e com resultados concretos, ampliando o processo de ensino e de aprendizagem, alcançando objetivos que contribuam para o desenvolvimento da autonomia e valorização profissional.

\section{REFERENCLAS BIBLIOGRÁFICAS}

ALVES, Nilda. "Cultura e cotidiano escolar". In: Revista Brasileira de Educação.

São Paulo, n.23, p.62-74, maio/ag. 2003.

BAKHTIN, Mikhail. Estética da Criação Verbal. São Paulo: Martins Fontes, 2003. BARROS, Manoel de. Cantigas Por Um Passarinho à Toa. Rio de Janeiro: Record, 2003. BENJAMIN, Walter. Passagens. Belo Horizonte: UFMG; São Paulo: Imprensa 
Oficial do Estado de São Paulo, 2009.

CAMPOS, Patrícia R. I. "A orientadora pedagógica, a atuação e a formação docente: um encontro com Alice e o Pequeno Príncipe”. 2010. 202fls. Dissertação (Mestrado em Educação) - Faculdade de Educação, Universidade Estadual de Campinas, Campinas, SP.

CERTEAU, Michel. A Invenção do Cotidiano, Artes de Fazer. 15 ed. Petrópolis: Vozes, 2008.

CHIAVENATO, Idelbrando. Gestão de Pessoas. 4. ed. São Paulo: Atlas, 1997.

CLEMENTI, Nilba. "A voz dos outros e a nossa voz: alguns fatores que intervêm na atuação do coordenador”. In: ALMEIDA, Laurinda Ramalho; PLACCO, Vera M. N. de Souza. (Orgs.). O Coordenador Pedagógico e o Espaço da Mudança. 3 ed. Sáo Paulo: Loyola, 2003.

CUNHA, Renata C. O. Barrichelo. "Pelas telas, pelas janelas: a coordenação pedagógica e a formação de professores nas escolas”. 2006. 272fl. Tese (Doutorado em Educação) - Faculdade de Educação, Universidade Estadual de Campinas, Campinas, SP.

FONTANA, Roseli A. Cação. "Como nos tornamos professores? Aspectos da constituição do sujeito como profissional da educação". 1997. Tese (Doutorado em Educação) - Faculdade de Educação, Universidade Estadual de Campinas, Campinas, SP.

GALLO, Silvio. "Acontecimento e resistência: educação menor no cotidiano da escola”. In: MARIGUELA, Márcio; CAMARGO, Ana Maria Faccioli de (Orgs). Cotidiano escolar: Emergência e Invenção. Piracicaba, SP: Jacintha Editores, 2007.

GEGLIO, Paulo César. "O papel do coordenador pedagógico na formação do professor em serviço”. In: PLACCO, Vera M. N. de Souza; ALMEIDA, Laurinda Ramalho (Orgs.). O Coordenador Pedagógico e o Cotidiano da Escola. 5 ed. São Paulo: Loyola, 2008.

GERALDI, João Wanderley. O Texto na Sala de Aula. 3. ed. São Paulo: Ática, 2003.

JOSSO, Marie-Christine. Experiências de Vida e Formação. São Paulo: Cortez, 2004.

LARROSA, Jorge, et al. Déjame que te Cuente. Ensayos Sobre Narrativa y Educación. Barcelona: Editorial Laertes, 1995.

PIERINI, Adriana Stella. "A (des)constituição da orientadora pedagógica na escola pública: uma trama de muitos fios, vários laços e alguns nós”. 2007. 160fl. Dissertação (Mestrado em Educação) - Faculdade de Educação, Universidade Estadual de Campinas, SP.

PRADO, Guilherme do V. T.; SOLIGO, Rosaura. Porque Escrever é Fazer História. Campinas, SP: Graf. FE, 2005.

SOUZA, Elizeu Clementino de. O Conhecimento de Si: Estágio e Narrativas de Formação de Professores. Rio de Janeiro: DP\&A; Salvador: UNEB, 2006.

WITTIZORECKI, Elisandro S., et al. "Pesquisar exige interrogar-se: A narrativa como estratégia de pesquisa e de formação do(a) pesquisador(a)". In: Revista Movimento. Porto Alegre, v. 12, n. 2, p. 9-33, maio/ag. 2006. 